\title{
Erratum to: Towards novel Cry toxins with enhanced toxicity/broader: a new chimeric Cry4Ba / Cry1Ac toxin
}

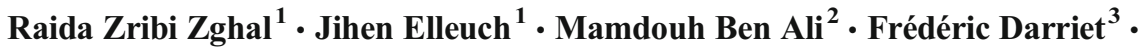 \\ Ahmed Rebai $^{4} \cdot$ Fabrice Chandre $^{3} \cdot$ Samir Jaoua $^{5} \cdot$ Slim Tounsi $^{1}$
}

Published online: 20 June 2017

(C) Springer-Verlag GmbH Germany 2017

Erratum to: Appl Microbiol Biotechnol (2017) 101:113-122 DOI 10.1007/s00253-016-7766-3

The original version of this article inadvertently contained mistake.

Results section, in the Fig. 3:

- A wrong unit for the molecular weight of the proteins was shown: "kb" should be read as "kDa".

- "a" should be read "A" and "b" should be read "B".

The online version of the original article can be found at http:dx.doi. org/10.1007/s00253-016-7766-3.

Raida Zribi Zghal

raida.zribi@cbs.rnrt.tn

1 Laboratory of Biopesticides, Centre of Biotechnology of Sfax, University of Sfax, P.O. Box "1177", 3018 Sfax, Tunisia

2 Laboratoire de Microorganismes et de Biomolécules, Centre de Biotechnologie de Sfax, Université de Sfax, Sfax, Tunisia

3 Institut de Recherche pour le Développement (IRD), UMR MIVEGEC (UM1-UM2-CNRS 5290-IRD 224) Maladies Infectieuses et Vecteurs, Ecologie, Génétique, Evolution et Contrôle, Laboratoire de Lutte contre les Insectes Nuisibles (LIN), Montpellier, France

4 Research Group on Molecular and Cellular Screening Processes, Laboratory of Microorganisms and Biomolecules, Centre of Biotechnology of Sfax, Sfax, Tunisia

5 Department of Biological \& Environmental Sciences, College of Arts and Sciences, Qatar University, P.O. Box: 2713, Doha, Qatar
A

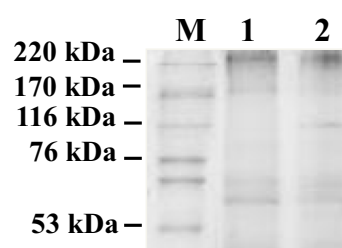

B

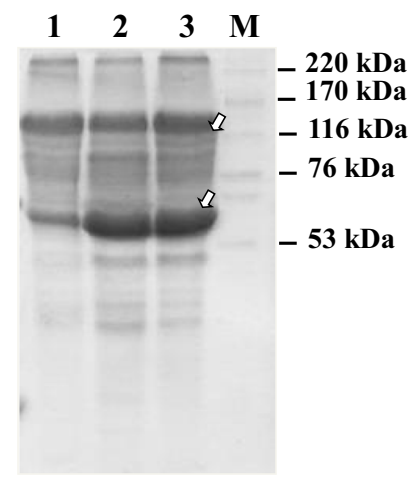

Fig. 3 